\title{
Climate change over UK cities: the urban influence on extreme temperatures in the UK climate projections
}

\author{
William J. Keat ${ }^{1}$ [D . Elizabeth J. Kendon ${ }^{1} \cdot$ Sylvia I. Bohnenstengel ${ }^{2}$
}

Received: 31 March 2021 / Accepted: 7 July 2021 / Published online: 29 September 2021

(c) Crown 2021

\begin{abstract}
Increasing summer temperatures in a warming climate will increase the exposure of the UK population to heat-stress and associated heat-related mortality. Urban inhabitants are particularly at risk, as urban areas are often significantly warmer than rural areas as a result of the urban heat island phenomenon. The latest UK Climate Projections include an ensemble of convection-permitting model (CPM) simulations which provide credible climate information at the city-scale, the first of their kind for national climate scenarios. Using a newly developed urban signal extraction technique, we quantify the urban influence on present-day (1981-2000) and future (2061-2080) temperature extremes in the CPM compared to the coarser resolution regional climate model (RCM) simulations over UK cities. We find that the urban influence in these models is markedly different, with the magnitude of night-time urban heat islands overestimated in the RCM, significantly for the warmest nights (up to $4{ }^{\circ} \mathrm{C}$ ), while the CPM agrees much better with observations. This improvement is driven by the improved land-surface representation and more sophisticated urban scheme MORUSES employed by the CPM, which distinguishes street canyons and roofs. In future, there is a strong amplification of the urban influence in the RCM, whilst there is little change in the CPM. We find that future changes in soil moisture play an important role in the magnitude of the urban influence, highlighting the importance of the accurate representation of land-surface and hydrological processes for urban heat island studies. The results indicate that the CPM provides more reliable urban temperature projections, due at least in part to the improved urban scheme.
\end{abstract}

\section{Introduction}

In a warming climate, the proportion of the UK population that will be exposed to heat stress and therefore heatrelated mortality risk is expected to increase (Hajat et al. 2014; Heaviside et al. 2016; Vicedo-Cabrera et al. 2018; Lo et al. 2019). As well as having high population densities, urban areas are often significantly warmer than surrounding rural areas as a result of the urban heat island (UHI) phenomenon (Oke 1982; Arnfield 2003), meaning they are particularly sensitive to extreme temperatures. During the 2003 European summer heatwave, it was estimated that there were 2091 excess deaths in the UK, including 616 in London and 130 in the West Midlands region (Johnson et al. 2005),

William J. Keat

william.keat@metoffice.gov.uk

Met Office, FitzRoy Road, Exeter, Devon EX1 3PB, UK

2 Met Office@Reading, Meteorology Building, University of Reading, Reading, UK of which 52\% were attributable to the UHI (Heaviside et al. 2016). By 2050, $90 \%$ of the UK population is projected to live within urban areas (UN DESA/Population Division 2018). It is therefore essential to understand how climate change will impact urban climates, particularly temperature extremes.

The latest generation of climate models, such as the UK Climate Projections (UKCP) Local $(2.2 \mathrm{~km})$ projections, recently released by the UK Met Office (Kendon et al. 2019), are now being run at a similar resolution to operational weather forecast models. At km-scales, the land surface atmosphere exchange in cities is much better resolved. This represents a step change in climate modelling capability and allows, for the first time, credible urban climate information at the city-scale. This is essential to inform policy makers of expected changes to urban climates, and could be used by health agencies and urban planners to mitigate future climate risks. 


\subsection{Urban climates}

Urban areas modify their local climate by altering the surface energy balance (Oke 1982; Arnfield 2003; Bohnenstengel et al. 2011). The convoluted form of urban surface areas (i.e., street canyons), results in a larger surface area in contact with the atmosphere, leading to additional absorption, reflection and emission of radiation, and turbulent flux exchanges compared to a planar area. The impact of street canyons can result in a lower effective albedo at canyon top than the urban surface material albedo. Usually, the effective albedo of a canyon is reduced compared to a planar surface with similar material properties and albedo leading to more effective absorption of radiation (direct and diffuse) during daytime (Masson 2000; Oke et al. 2017). During the night, a reduction in the efficiency of longwave emission leads to heat being trapped within the urban canopy. Urban materials and the urban canopy are characterised by large heat capacities and a large thermal inertia, respectively, leading to storage of energy during the daytime that can be released back into the atmosphere at night (Bohnenstengel et al. 2011). In addition, non-porous urban surfaces promote surface run-off which, combined with reduced vegetation in some cities, limits the cooling effect of evapotranspiration and alters the timing and amplitude of sensible heat fluxes throughout the course of the day (Oke 2002; Bohnenstengel et al. 2011). The urban canopy has a larger thermal inertia than rural vegetated areas and maintains a positive sensible heat flux late into the night due to the thermal inertia offsetting the radiative cooling of the surfaces, contributing to the UHI effect. Anthropogenic heat sources, such as those from heating and air conditioning also contribute (Allen et al. 2011; Sailor 2011; Bohnenstengel et al. 2014).

During the day, urban areas store incoming solar radiation and the urban fabric warms. Once the urban fabric is warmer than the atmosphere, a sensible heat flux starts to warm the atmosphere; the phase of the sensible heat flux is moderated by the heat capacity of the urban fabric. The rural land surface is characterised by a smaller heat capacity and therefore warms up more quickly during the day, leading to a positive sensible heat flux earlier in the day. At night, the small heat capacity of the rural land surface means that less energy is available to offset radiative cooling. In an urban environment, however, the larger heat capacity offsets the radiative cooling for longer which in turn leads to a prolonged positive sensible heat flux and higher air temperatures at night.

The UHI effect is most pronounced during calm and clear nights when local effects dominate the boundary layer structure (Oke 2002). The magnitude of the UHI is often quantified in terms of the urban heat island index (UHII), an estimate of the urban increment on local climate. In the UK, night-time UHIIs up to $7{ }^{\circ} \mathrm{C}$ have been observed for London
(Watkins et al. 2002; Wilby 2003) and $5{ }^{\circ} \mathrm{C}$ for Birmingham (Heaviside et al. 2015). In Manchester, daytime UHIIs of $3{ }^{\circ} \mathrm{C}$ and night-time UHIIs of $5{ }^{\circ} \mathrm{C}$ for summer days have been observed (Smith et al. 2011). In general, the intensity of urban heat island effect is largest for night-time minimum temperatures, which is important for public health because warm nights limit relief and inhibit recovery from heat stress during the daytime [e.g., Fischer and Schär (2010)].

A number of studies have attempted to quantify changes in UK urban climates under climate change, with mixed results. By coupling a simple urban scheme to a regional climate model, McCarthy et al. (2012) investigated future changes in rural and urban temperatures in a regional climate model and found that rural and urban temperatures increased by similar amounts during both the daytime and night-time, with the daytime London UHII decreasing by $0.1^{\circ} \mathrm{C}$ or less by 2050 and the nocturnal UHII unchanged. However, by incorporating a parameterisation for urban surfaces into the Community Land Model as part of the Community Climate System Model, Oleson et al. (2011) examined changes in global urban and rural temperatures out to the end of the 21 st century. They found that although both urban and rural areas warm substantially, rural areas warm slightly more than urban, particularly at night due to different responses of rural and urban areas to increased long-wave radiation from a warmer atmosphere, resulting in a decrease in the UHII. Using the UKCP18 $12 \mathrm{~km}$ regional climate projections, Lo et al. (2020) estimate 1981-2079 trends in summer daytime and night-time urban and rural temperatures for the 10 largest UK cities by population. They find that night-time temperatures are set to increase more rapidly, and daytime temperatures more slowly, for urban areas compared to rural areas. This net effect is an enhancement of the night-time UHI by $0.01-0.05{ }^{\circ} \mathrm{C}$ per decade in all cities, in contrast to the decrease in urban and rural contrast found by Oleson et al. (2011). The opposite is found for daytime temperatures with rural temperatures warming more than urban temperatures, leading to decrease in the daytime UHI intensity of between -0.004 and $-0.05{ }^{\circ} \mathrm{C}$ per decade for all but one city.

There is a lack of consensus on future changes in rural and urban warming and the urban influence on those changes. In this paper, we analyse the latest UK Climate Projections to investigate the urban influence on extreme temperatures, and how it is expected to change in future.

\section{The UK climate projections}

UKCP18 are the latest set of climate projections for the UK, recently released by the UK Met Office and include probabilistic projections, new global projections and higher resolution Regional (European) projections (Lowe et al. 2018; Murphy et al. 2018). These were designed to replace 
the previous UKCP09 scenarios (Jenkins et al. 2010). In addition, a new set of Local (UK) "convection-permitting" model (CPM) projections were released in September 2019, providing even higher resolution and new capability in terms of local extremes. The Global projections consist of 28 realisations, 15 of which are from a perturbed parameter ensemble (PPE) of the Hadley Centre coupled model HadGEM3GC3.05 and 13 of which are selected members from the CMIP5 set (Murphy et al. 2018). The UKCP Regional projections consist of 12 PPE members at $12 \mathrm{~km}$ horizontal resolution over a European domain, driven by members of the Hadley Centre global model PPE. The UKCP CPM projections consist of a 12-member ensemble at $2.2 \mathrm{~km}$ horizontal resolution, driven at the boundaries by the $12 \mathrm{~km}$ Regional Climate Model (RCM). The CPM is based on the operational UKV model used for weather forecasting, and due to its high resolution is able to better represent small scale processes in the atmosphere (Kendon et al. 2019). This includes convection, which is represented explicitly in the CPM without the need for a parameterisation scheme, leading to a better representation of hourly rainfall including extremes [e.g., Kendon et al. (2014)]. The $2.2 \mathrm{~km}$ grid spacing also allows surface features to be better resolved including mountains, coastlines and cities. The CPM ensemble gives a first estimate of uncertainty in future changes at local and hourly scales. Specifically, it samples uncertainty in the large-scale conditions arising from uncertainty in the driving global and regional models and uncertainties arising from internal climate variability, but not uncertainty in the convective-scale model physics itself. The projections analysed here are based on the RCP8.5 scenario (Murphy et al. 2018).

\subsection{Key differences between the CPM and RCM configurations}

While the RCM and CPM share the majority of their main physical components, there are some notable differences between the model configurations. One of these is their representation of the urban surface. Both use the Joint UK Land Environment Simulator [JULES, Best et al. (2011)] to model land surface and sub-surface soil processes. This uses a land-surface tiling scheme, where the surface energy balance is calculated separately for each surface tile and then aggregated using the blending height concept (Essery et al. 2003) to give grid box averaged fluxes. The grid box average flux then provides the lower boundary condition to the first atmospheric model level. The RCM uses a single slab tile to represent urban areas using the Best (2005) urban scheme. Here, the standard surface energy balance equation for vegetative surfaces is used but with modified parameters that are appropriate for an urban surface, such as reduced albedo and increased heat storage capacity. In contrast, the CPM takes a more sophisticated approach, using the Met Office
Reading Urban Surface Exchange Scheme (MORUSES). Two urban tiles are used to represent street canyon and roof facets (Porson et al. 2010a, b), allowing the surface energy balances to be calculated separately for the street canyon and roof, including differences in their heat storage capacity. The surface energy balance for the canyon and for the roof depends on effective surface parameters calculated from the morphology and material properties of different cities (Porson et al. 2010a). Using this approach, the radiative exchange within the street canyon is represented by bulk, effective values of the albedo and emissivity, accounting for shadowing and multiple reflections (Harman et al. 2004b; Porson et al. 2010a). Turbulent scalar fluxes are represented with a resistance network, which accounts for the recirculating flow set up in the street (Harman et al. 2004a), while storage of heat by building surfaces is represented by a thermal reservoir that depends on urban geometry and surface properties (Porson et al. 2010a). Unlike the Best (2005) scheme, anthropogenic heat emissions are included, ranging from a minimum of $\approx 17 \mathrm{Wm}^{-2}$ in August to a maximum of $\approx 26 \mathrm{Wm}^{-2}$ in December, scaled by the urban fraction (Hertwig et al. 2020).

Land cover in the CPM is defined from the high-resolution $(25 \mathrm{~m}$ ) Centre for Ecology and Hydrology (CEH) land cover dataset (Fuller et al. 1994), which uses Institute of Terrestrial Ecology Landsat-derived cover types over Great Britain and $1 \mathrm{~km}$ resolution International Geosphere-Biosphere Programme (IGBP) dataset (Walters et al. (2019) and references therein) for the rest of the UK. The RCM uses the IGBP land-cover for all of the UK. The difference between the urban fractions in these datasets is shown in Fig. 1. In general, IGBP urban fractions for cities in the UK are larger in magnitude and extent than in the CEH dataset. Land use varies through time in both the CPM and RCM, although the urban fraction is held constant. In particular, the fractions of grasses and trees vary as prescribed by a time-varying component, and given differences in the baseline land cover dataset this can lead to differences in the land use changes between the CPM and RCM, as described in Kendon et al. (2019). Full details of model differences can be found in (Kendon et al. 2019).

\section{Summer daily temperature extremes}

First, we examine how well each model represents daily temperature extremes of the present-day climate (1981-2000). Figure 2 shows the 99th percentile of summer (JJA) daily maximum temperatures for the UK in the CPM and RCM, compared to National Climate Information Centre (NCIC) gridded climate observations for the UK, HadUK-Grid (Hollis et al. 2019). While the NCIC temperatures are available on $1 \mathrm{~km}$ grid, they, and the $2.2 \mathrm{~km} \mathrm{CPM}$ data have been 
Fig. 1 Urban fractions in the IGBP (left) and CEH (middle) land cover datasets, and difference between them (right)
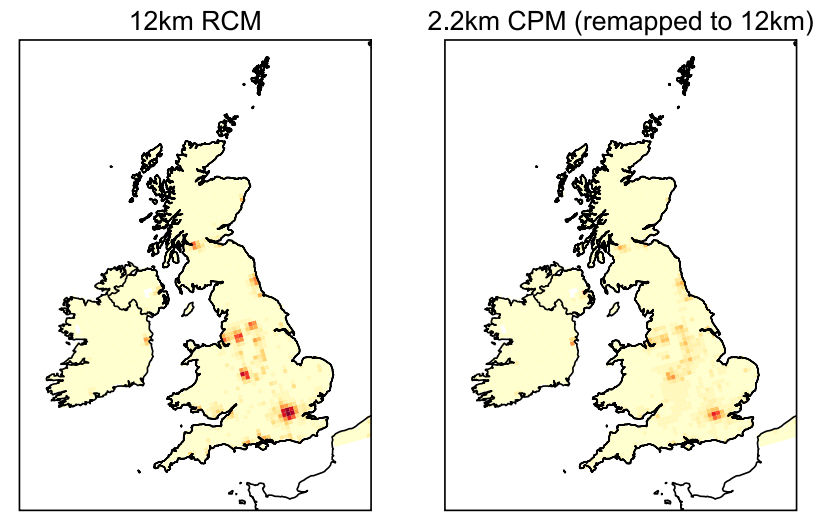

$2.2 \mathrm{~km} \mathrm{CPM} \mathrm{-} 12 \mathrm{~km}$ RCM

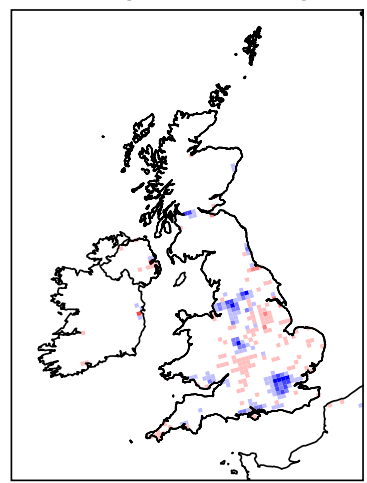

\begin{tabular}{llllllllllll}
\hline 0.0 & 0.1 & 0.2 & 0.3 & 0.4 & 0.5 & 0.6 & 0.7 & 0.8 & 0.9 & 1.0
\end{tabular} \begin{tabular}{lllllllllllllllllllll}
\hline 0.0 & 0.1 & 0.2 & 0.3 & 0.4 & 0.5 & 0.6 & 0.7 & 0.8 & 0.9 & 1.0 & $-0.36-0.28$ & $-0.20-0.12-0.04$ & 0.04 & 0.12 & 0.20 & 0.28 & 0.36
\end{tabular}
Fig. 2 a 99th percentile of summer (JJA) daily maximum temperatures in the NCIC observations and ensemble mean 99th percentile for the $\mathbf{b}$ RCM and c CPM for 1981-2000. Panels d-f show the difference between the CPM and RCM, and the RCM and CPM biases respectively

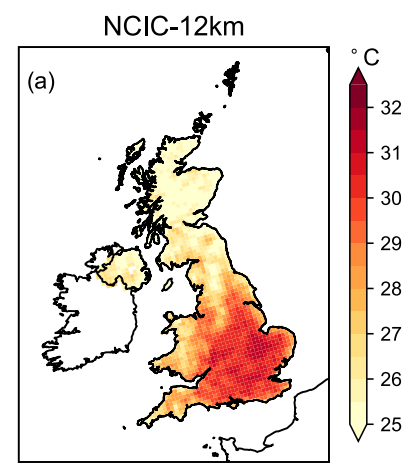

CPM-RCM

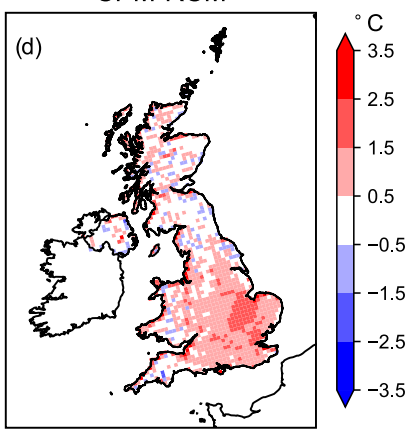

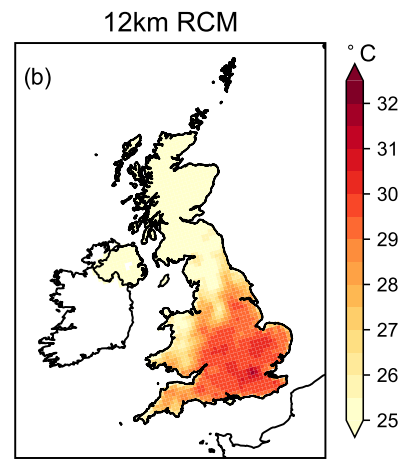

$12 \mathrm{~km} \mathrm{RCM} \mathrm{bias}$

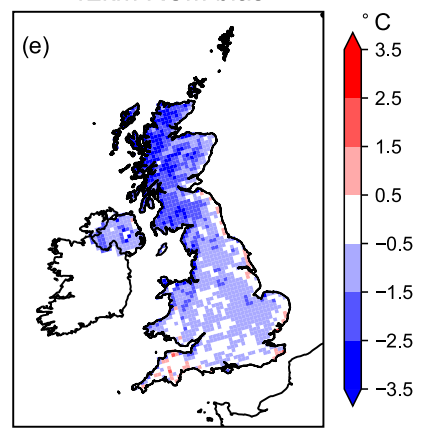

$2.2 \mathrm{~km} \mathrm{CPM}$

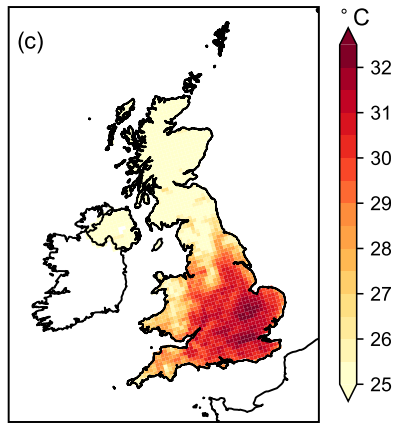

$2.2 \mathrm{~km}$ CPM bias

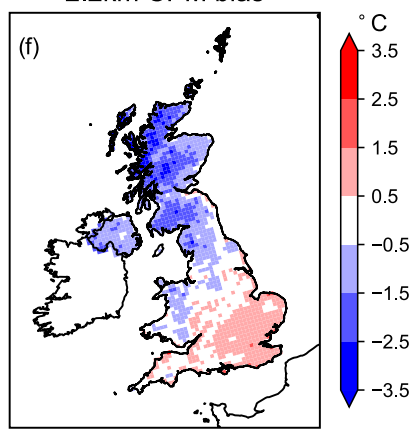

regridded to $12 \mathrm{~km}$ for like-for-like comparisons between the datasets. The 99th percentile corresponds to approximately the hottest day in a typical summer, so are referred to as hot days hereafter. Both models accurately represent the spatial distributions of hottest day temperatures, however, temperatures in the RCM are too cool across the whole UK, particularly Scotland, while in the CPM they are too cool in northern England and Scotland and too warm in the southern and eastern England. Hottest day temperatures in the RCM and CPM are similar across northern England and Scotland, but the CPM is warmer by $1-2{ }^{\circ} \mathrm{C}$ across southern and eastern England.

Figure 3 shows the same as Fig. 2, but for the 99th percentile of JJA daily minimum temperatures (warm nights). As expected, the urban heat island effect is more pronounced in the minimum temperatures (Oke 2002). Urban areas are significantly warmer in the RCM than both the observations and the CPM, with most major UK cities clearly visible against their surrounding rural temperatures. RCM biases over London are in excess of $2{ }^{\circ} \mathrm{C}$, while Birmingham, Manchester and Leeds are $>1$ ${ }^{\circ} \mathrm{C}$ warmer than observations. The CPM has a slight warm bias $\left(\approx 0.5^{\circ} \mathrm{C}\right)$ in hot summer nights across most of the country, while hot nights in the RCM are typically cooler $\left(\approx 1{ }^{\circ} \mathrm{C}\right)$ across rural areas in all but the south east of England, where it is $\approx 0.5^{\circ} \mathrm{C}$ warmer. In the CPM, London is too warm by $\approx 0.5-1{ }^{\circ} \mathrm{C}$ compared to observations. Warm summer nights are warmer across the whole UK compared to the RCM, except over major UK cities where they are up to $1{ }^{\circ} \mathrm{C}$ cooler. 
Fig. 3 As for Fig. 1, but for summer daily minimum temperatures
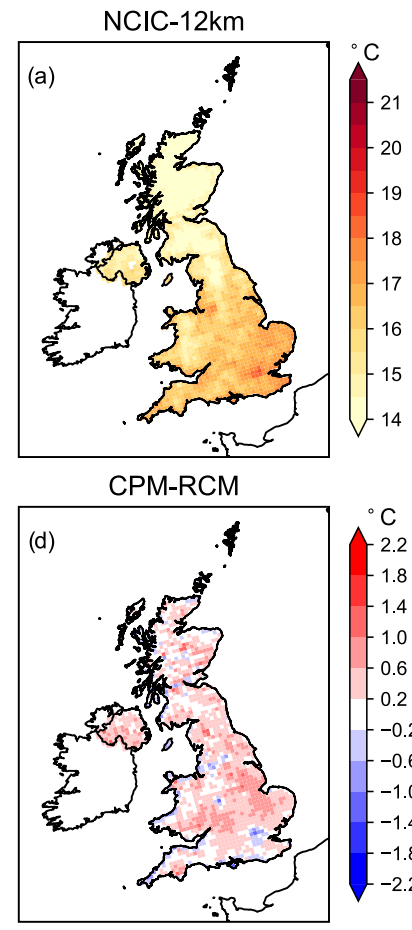

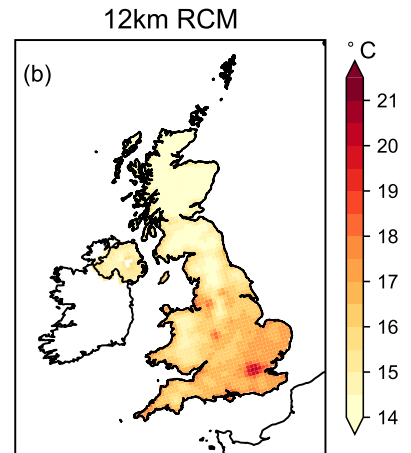

$12 \mathrm{~km}$ RCM bias

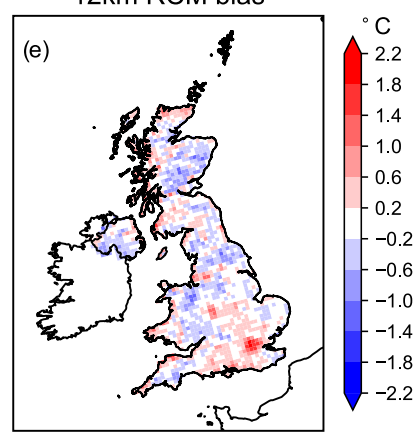

$2.2 \mathrm{~km} \mathrm{CPM}$

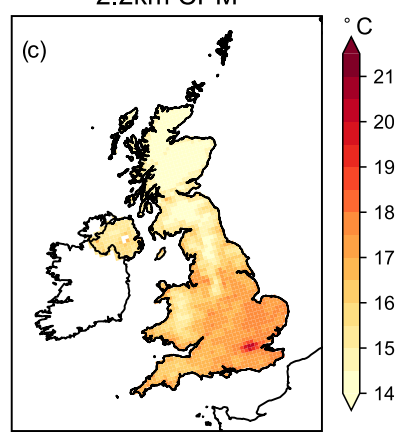

$2.2 \mathrm{~km}$ CPM bias

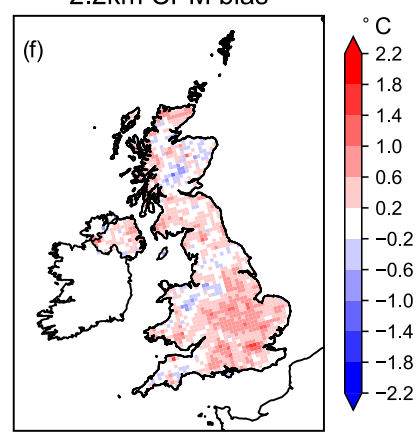

In order to investigate the urban influence on hot summer days and warm summer nights, a new technique has been developed that enables the extraction of the urban signal in gridded datasets.

\section{Urban signal extraction}

In this section, a new method is described that allows the urban influence on temperature to be extracted for all grid boxes by producing an estimate of the rural temperature at the locations of urban areas across the UK. The process is as follows:

1. Urban areas are identified as grid boxes where the subgrid scale impervious urban land cover fraction (from the respective land cover information i.e., IGBP or CEH) exceeds a certain threshold. Here, we use a threshold of 0.1 , as it was found to accurately identify major UK urban areas (the sensitivity to this choice is discussed in Sect. 7). These urban areas, as well as sea points are then masked.

2. A linear interpolation is then performed, using the remaining "rural" land grid boxes to estimate the missing values (corresponding to the urban areas) to create a rural-reference dataset.

3. The difference between the original and rural-reference datasets is the urban influence on temperature at each grid point.
This method has several advantages over existing methodologies. Firstly, it allows for the urban influence to be extracted for any urban area, regardless of its size or location. It also avoids the requirement to choose appropriate rural and urban reference points, which can be situated tens of km apart and be affected by other local meteorological factors. Instead, this method provides co-located (and therefore spatially consistent) urban and rural temperature estimates. In what follows, this methodology is applied at the native resolution of each dataset, before the extracted urban signals are regridded to $12 \mathrm{~km}$ for comparison. The limitations of this method are discussed in Sect. 7.

\section{Urban influence on present-day and future extreme temperatures}

In this section, we apply the above technique to extract the urban influence on daily maximum and minimum temperatures on each day in the present-day and future (2061-2080) timeslices. Figure 4 shows the present-day and projected changes in ensemble-mean temperature on hot summer days (defined as days when the maximum temperature exceeds the 99th percentile during JJA). The rural-reference temperatures are the mean of the rural-reference temperature dataset sub-sampled on these days. This analysis neglects the fact that daily minimum and maximum temperatures can occur at different times for urban and rural areas, with diurnal cycle phasing differences and their impact on UHII estimates explored in Sect. 6.2. Note to correct for positional errors 
$12 \mathrm{~km} \mathrm{RCM}$
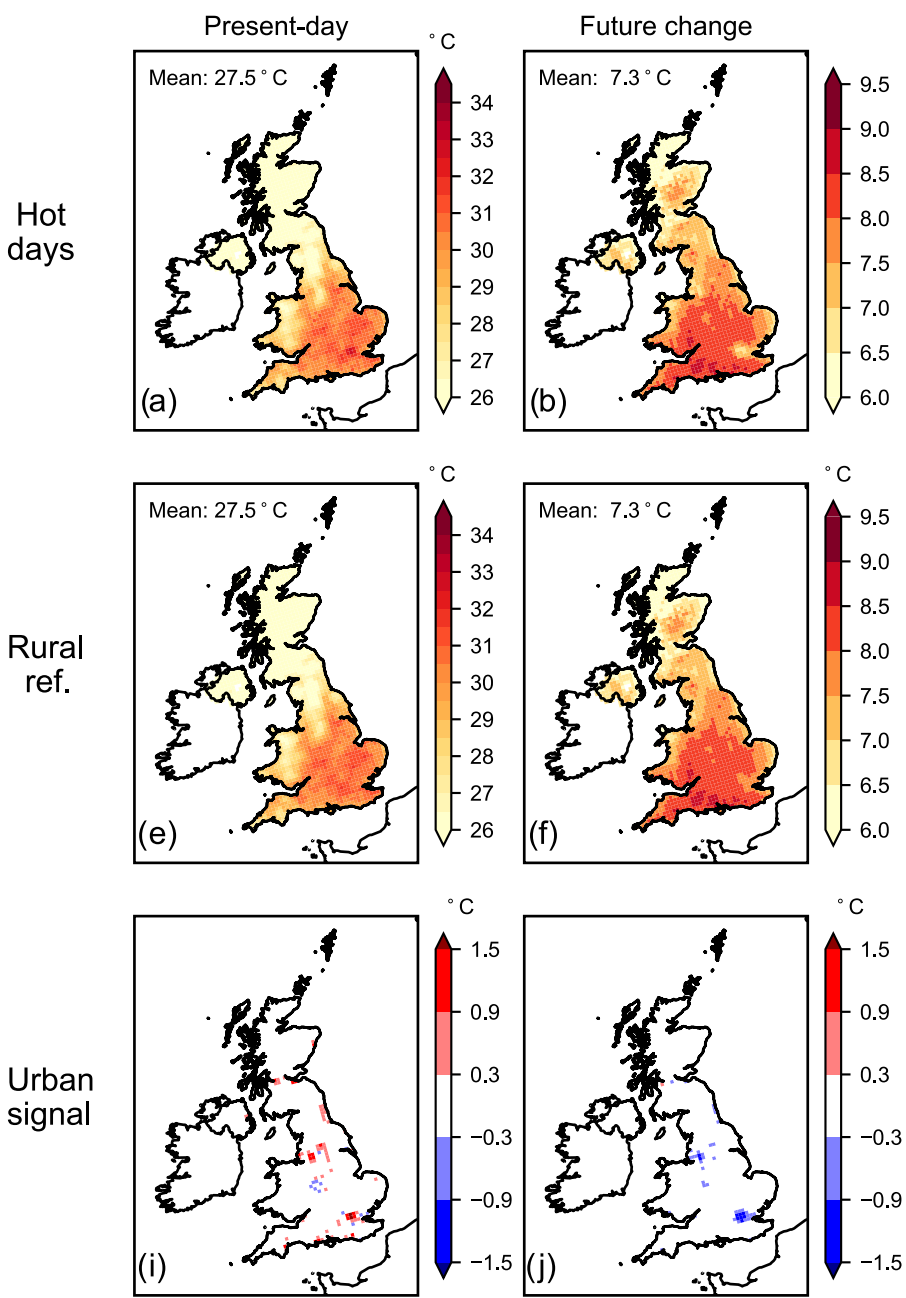

(i)

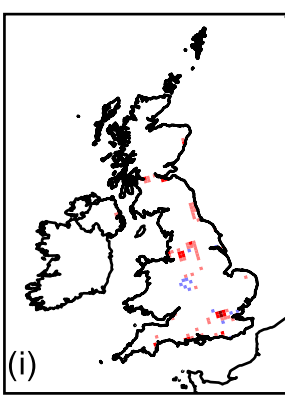

Urban signal

Fig. 4 Present-day and future changes in summer hot days for the urban and rural-reference temperature datasets for the RCM and CPM (see text for definition). Panels $i$ and $k$ show the urban signal, calcu-

in the IGBP land-use data used in the RCM (Husak et al. 1999), a systematic shift of $3.5 \mathrm{~km}$ east and $3.5 \mathrm{~km}$ south (Stuart Webster, personal communication) is applied to the RCM. The shifted RCM data is then linearly interpolated back onto the original RCM grid before comparison with the CPM or observations. The upshot of this is that urban fractions and temperatures (and therefore urban signals) are smoothed, resulting in them likely being slightly underestimated in the RCM. In the RCM, in the present-day, urban temperatures over London, Manchester and Leeds are $>1{ }^{\circ} \mathrm{C}$ warmer than rural temperatures (panel $i$ ). In terms of future changes, rural temperatures are projected to increase by $8-9{ }^{\circ} \mathrm{C}$ across southern and southwestern UK and between $6-8{ }^{\circ} \mathrm{C}$ elsewhere. However, for the urban signal, there are clear local minima in the projected changes in the cities of Leeds, Manchester and, particularly, London, with rural areas warming more than urban areas by $\approx 1-1.5^{\circ} \mathrm{C}$ (panel
$2.2 \mathrm{~km} \mathrm{CPM}$
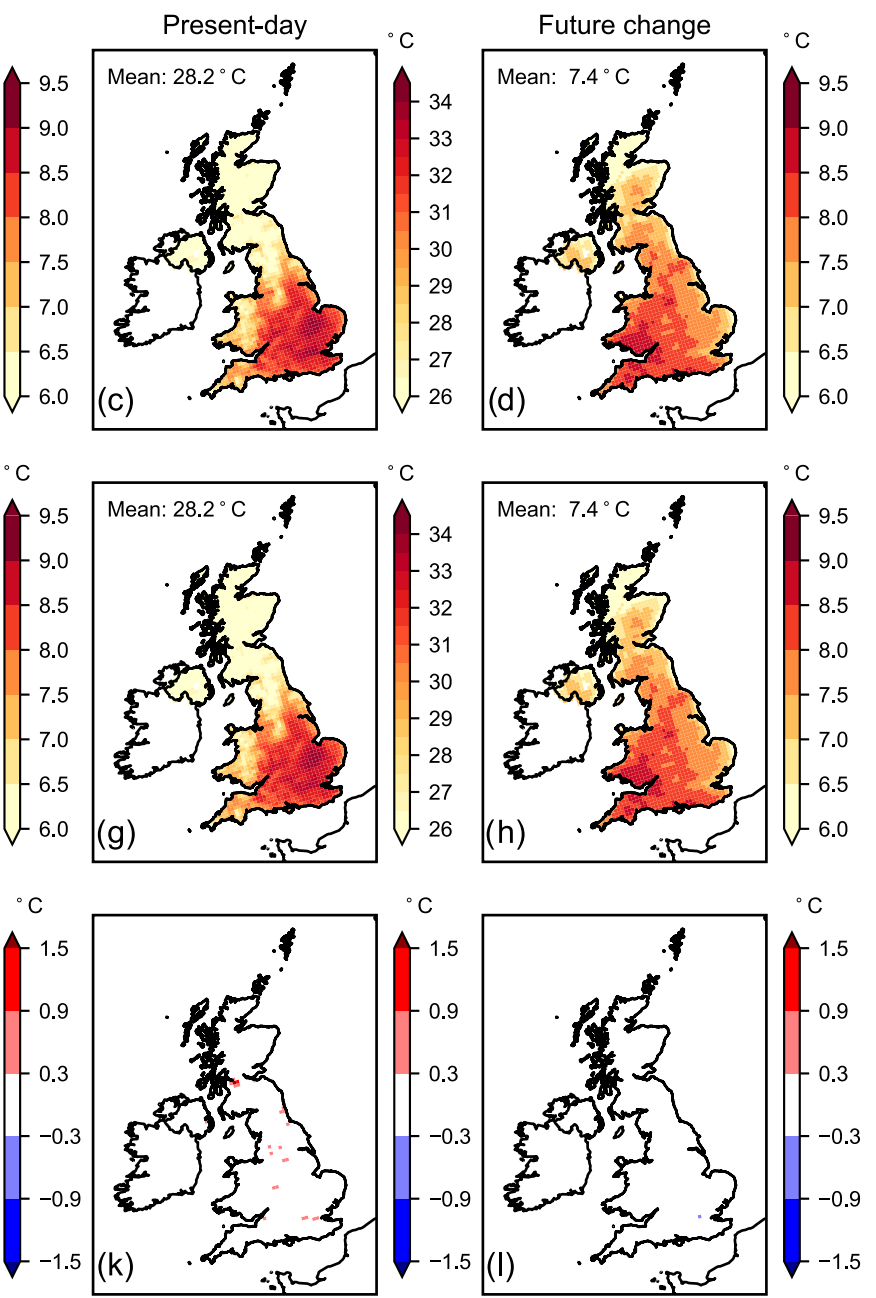

lated as the difference between the original and rural-reference datasets, and $j$ and $l$ future changes in the urban signal for the RCM and CPM respectively

$j$ ). This differential warming, and associated reduction of the daytime UHII for these cities is consistent with the results of (Lo et al. 2020) which note similar behaviour in the UKCP RCM. However, the behaviour in the CPM is quite different. In the present-day, the hottest days are typically warmer than the RCM, potentially the result of drier soils in the CPM (Kendon et al. 2019). Urban temperatures are $\approx 0.5-1^{\circ} \mathrm{C}$ warmer than rural temperatures (panel $k$ ). In future, urban and rural temperatures are projected to increase by similar amounts, resulting in a negligible future change in the urban signal (panel $l$ ). Rural-reference temperatures increase relatively more in the RCM than in the CPM across much of England, which is related to the larger drying of future RCM soils compared to the CPM (see Sect. 7). The UHII signals are larger in area and magnitude in the RCM than the CPM, which is likely caused by a combination of the different land cover datasets (which explains the different urban 
$12 \mathrm{~km} \mathrm{RCM}$
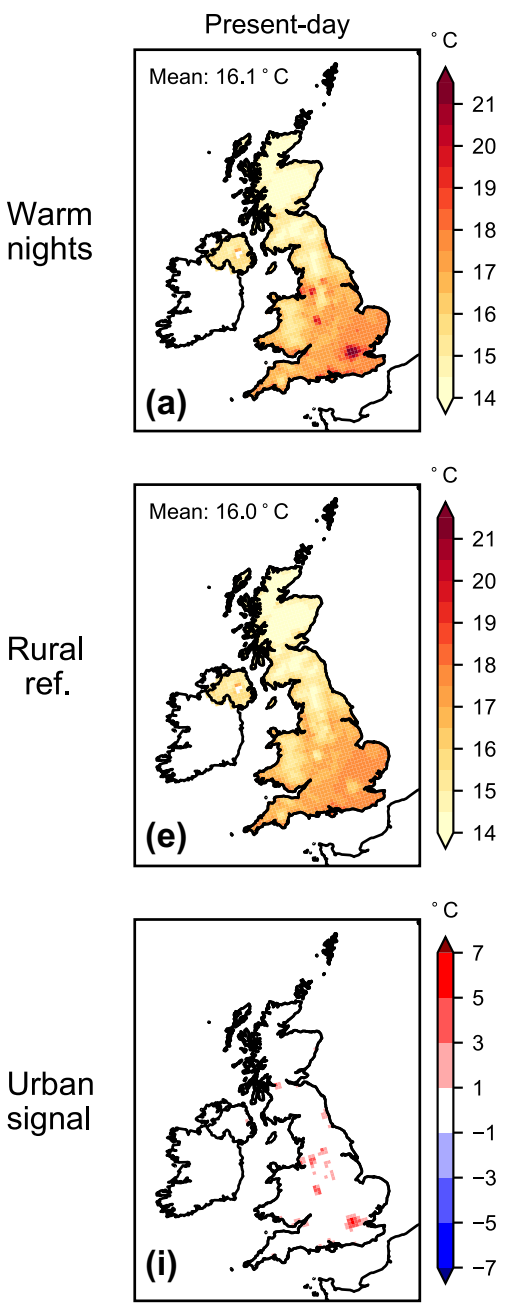
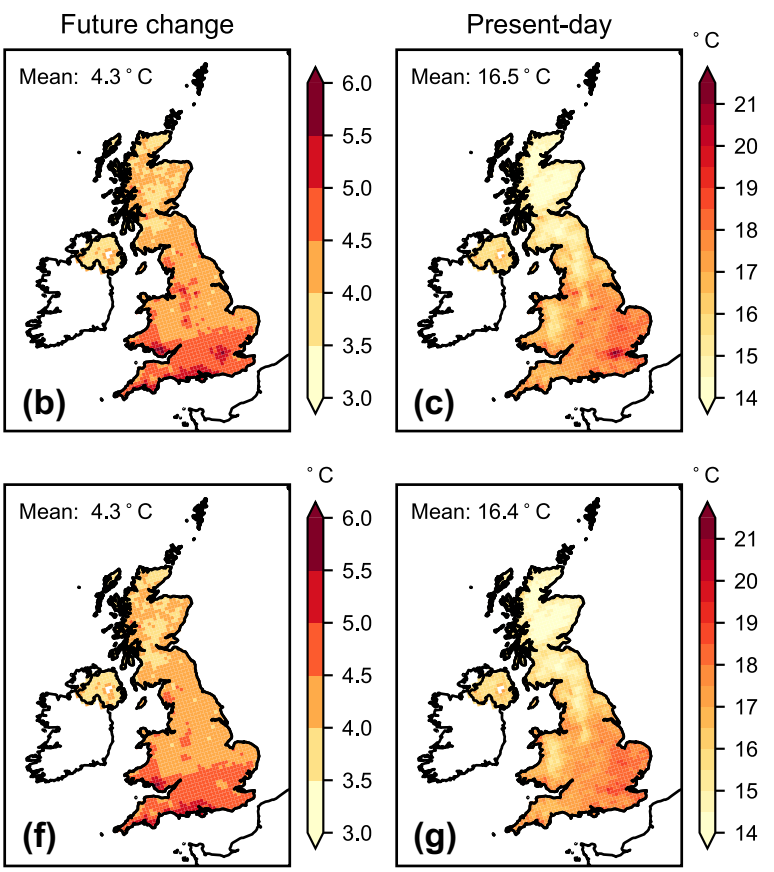

(d)
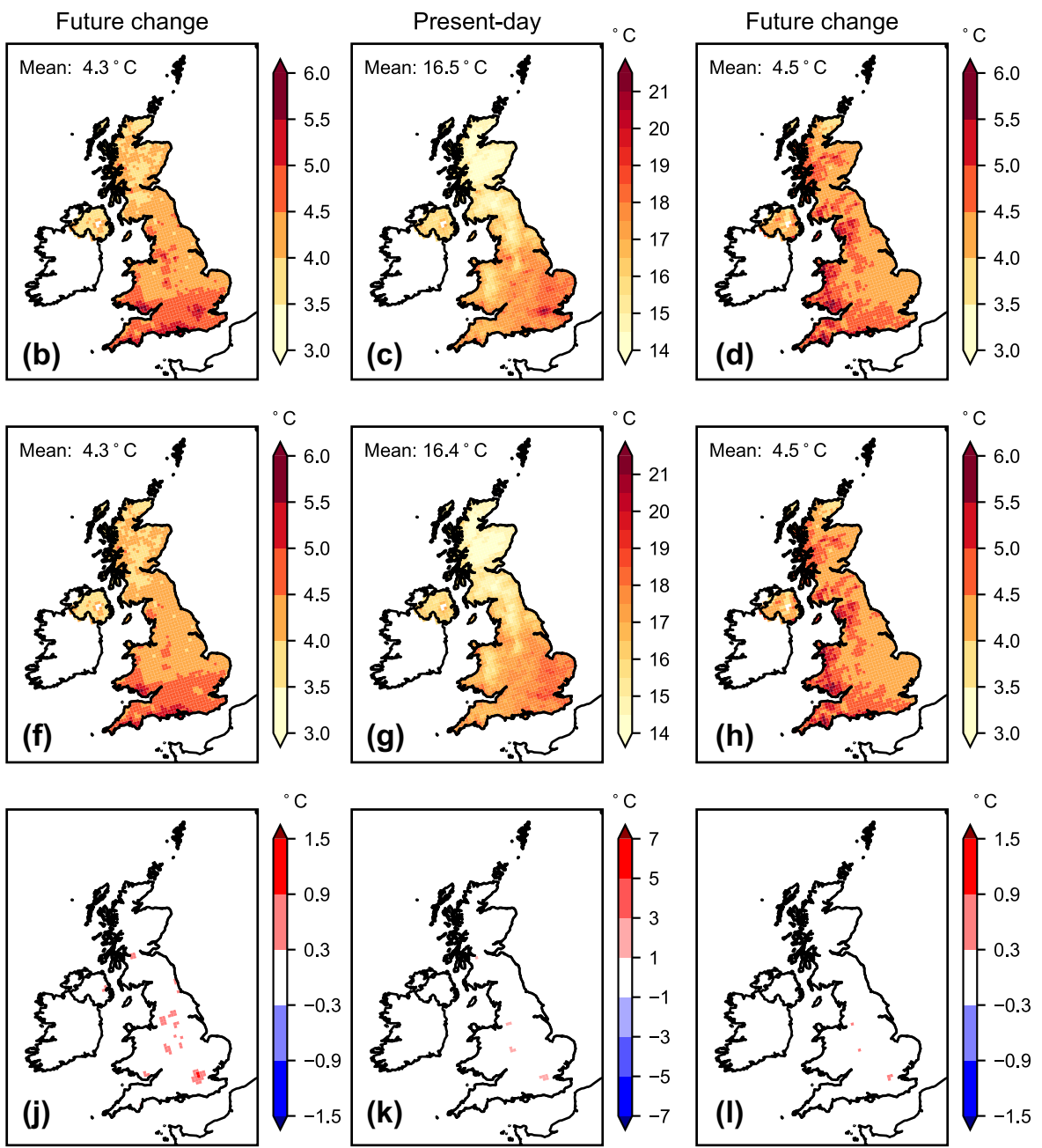

Fig. 5 As for Fig. 4, but for daily minimum temperatures

area spatial extent in the RCM over Great Britain) as well as the impact of the different urban schemes used in these models (see Sect. 2.1). This will be discussed further in Sect. 7.

Present-day and projected changes in daily minimum temperatures are shown in Fig. 5. Small dips in the rural-reference temperatures that can be seen over some cities relate to the mismatch in timing between when warm nights occur for urban and rural points, as described above. However, in the context of the urban signal, these are small. In the RCM, night-time urban temperatures are significantly warmer than rural temperatures with most major UK cities between 2 and $5{ }^{\circ} \mathrm{C}$ warmer than surrounding rural areas (panel $i$ ). Rural temperatures are projected to warm the most across the southern UK $\left(\approx 5^{\circ} \mathrm{C}\right)$, decreasing to $4{ }^{\circ} \mathrm{C}$ for northern $\mathrm{UK}$ and $3.5^{\circ} \mathrm{C}$ for Scotland. The projected changes in the urban temperatures are consistently up to $1{ }^{\circ} \mathrm{C}$ larger than the rural changes for most major UK cities (panel $j$ ). For the $\mathrm{CPM}$, major cities in the present-day are up to $1.5^{\circ} \mathrm{C}$ warmer than their surroundings (panel $k$ ). In the future, both urban and rural minimum temperatures are projected to increase by $4-5^{\circ} \mathrm{C}$. There is some evidence of a greater warming of $\approx 0.5^{\circ} \mathrm{C}$ for central London and Manchester compared to rural areas, however for all other cities the change in the urban signal is small $\left(<0.2^{\circ} \mathrm{C}\right)$. Compared to the $\mathrm{RCM}$, the urban signal in the CPM is significantly less (approximately a factor of 3). Interestingly, unlike the RCM, there is not a strong amplification of the urban effect in the CPM in the future. This behaviour is likely driven by different representation of urban processes in the MORUSES urban scheme used by the CPM. In Sect. 6.2, the diurnal cycles of urban signals are investigated in order to better understand the underlying processes that are responsible for this behaviour. 

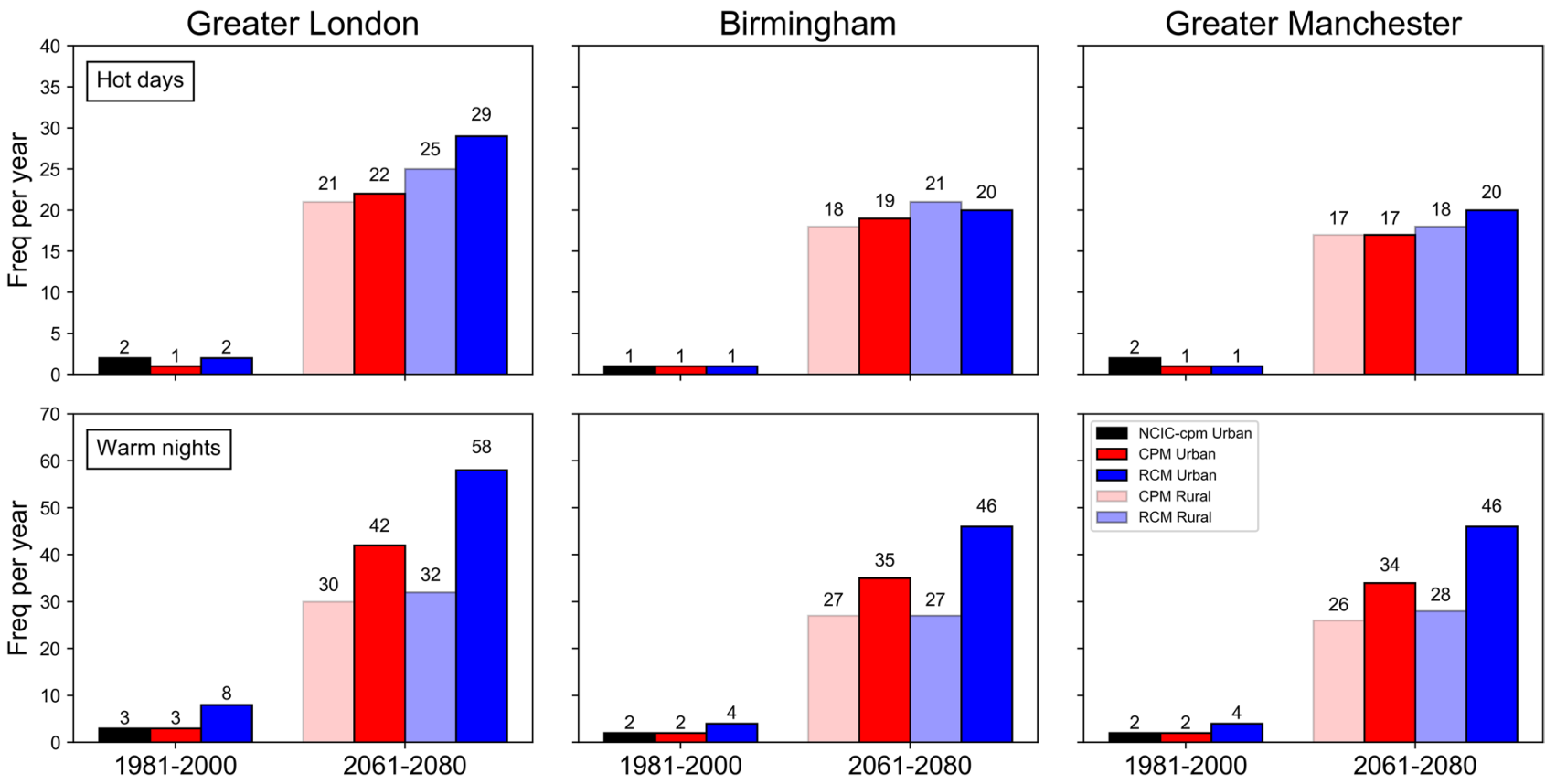

Fig. 6 Average annual frequency of hot days and warm nights for London, Birmingham and Manchester for NCIC observations (black), RCM (blue) and CPM (red). Lighter colours indicate frequency of

\subsection{Urban influence on present-day and future hot days and warm nights}

Figure 6 shows a comparison of the annual frequency of occurrence of hot summer days and warm nights in both the urban and rural-background datasets for the three largest UK cities by population: Greater London, Birmingham and Greater Manchester. Hot days are defined as days that the city-average daily maximum temperature exceeds the 99th percentile of the city-average 1981-2000 rural-background daily maximum temperatures, produced using the method in Sect. 4. Warm summer nights are defined similarly but against daily minimum temperatures. City grid boxes are extracted using city boundaries defined by the Office for National Statistics (Office for National Statistics 2013), where there is an overlap between the city's shapefile and the model grid box of more than 0.5. Since the ITE land-use dataset used in the CPM is known to be more accurate than IGBP, we use the CPM urban fractions to derive observed estimates of the UHII (NCIC-cpm). NCIC daily maximum and minimum temperature datasets were remapped from $1 \mathrm{~km}$ to the $2.2 \mathrm{~km}$ CPM grid, before extracting the urban signal and remapping that to the $12 \mathrm{~km} \mathrm{RCM} \mathrm{grid.}$

By definition, the number of rural hot days and warm nights is 1 for the present-day, so is not shown. The number of hot days is correctly reproduced by both models for rural and urban areas to within 1 per year for all cities. The greatest increase in the number of hot days is in the RCM over London, with rural and urban hot days increasing from 1 to 25 and 2 occurrence of rural hot days/warm nights. See text for hot day and warm night definitions

to 29 respectively. In terms of future changes, the number of hot days increases by a similar number for both urban and rural areas in the CPM for all three cities. The increase in the number of hot days is larger over urban areas for London and Manchester, while for Birmingham the increase in the number of rural hot days is larger $(+1)$ than urban hot days. For all cities, the number of hot urban and rural days increases more in the RCM than the CPM.

For all cities, there are too many warm nights over urban areas in the RCM compared to observations by a factor of $2-3$, whereas the CPM correctly captures the number of warm nights. In future, the number of warm urban and rural nights increases considerably. The increase in warm nights is always greater over urban than rural areas, and urban warm night frequency increases are always greater in the RCM. The largest increases are seen in London with an increase of 29 and 31 rural warm nights and 39 and 50 warm urban nights in the CPM and RCM respectively. This indicates that between one- and almost twothirds of future summertime nights will be warm nights. Interestingly, despite the large difference in the frequencies of warm urban nights in the RCM and the CPM, the absolute increase in the number of warm rural nights is similar. Given the better agreement of both models with observed estimates of warm rural nights and the CPM with observed estimates of warm urban nights, this suggests that urban areas in the RCM are too strongly influencing local temperatures. 


\section{Understanding the urban influence}

\subsection{Variation of the UHII with daily temperature}

To further investigate this model behaviour, in this section we study the urban influence not only during temperature extremes, but in a climatological sense as a function of city temperature. To obtain city-average estimates of the UHII, a time-series of city-average daily maximum or minimum temperatures is first created for each city (extracted using shapefiles, as described in Sect. 5.1). Then, on days on which the city-average temperature falls within each climatological percentile bin, the corresponding city-average UHII values on those days are subsampled. For the model estimates, this is done for each member, and the ensemble mean is taken.

Figure 7 compares observed and UKCP daytime and night-time UHII estimates for Greater London, Birmingham and Greater Manchester. As indicated by Fig. 2 and 3 , the daytime UHII (top) is significantly lower compared to the night-time UHII (bottom). For the present-day daytime over London and Manchester, there is a gradual increase in the UHII with increasing city temperature in the RCM up to $\approx 1{ }^{\circ} \mathrm{C}$ for the 99 th percentile. Meanwhile, for all cities, the CPM daytime UHII is less than $1{ }^{\circ} \mathrm{C}$ for all temperature percentiles, slightly overestimating compared to NCIC-cpm estimates. However, the CPM correctly represents the consistent strength of the urban influence with increasing city temperature. In future, CPM UHII estimates are unchanged for all London and Birmingham city temperature percentiles, but exhibit a slight decrease for the warmest days over Manchester. This is in contrast to the RCM, where, particularly for London and Birmingham, the UHII decreases with increasing city temperature (as much as $1^{\circ} \mathrm{C}$ for the hottest days). The urban influence on night-time city temperature extremes (top panels) is markedly different in the RCM compared to the CPM and observations. For the present-day in all three cities, the UHII is overestimated in the RCM for all city temperature percentiles, but this overestimation rapidly increases above the 90th percentile of night-time temperatures. For London, the UHII for the warmest nights is $4.5^{\circ} \mathrm{C}$ for London, $3.5^{\circ} \mathrm{C}$ for Birmingham and $4{ }^{\circ} \mathrm{C}$ for Manchester, compared to observed estimates closer to $0.5^{\circ} \mathrm{C}$. While the UHII is largest for the hottest nights in the CPM, the increase in UHII with temperature is smaller and more similar in magnitude to observed UHII estimates. In future, the behaviour of the RCM is amplified, with a further increase in the UHII with increasing city temperature for all cities
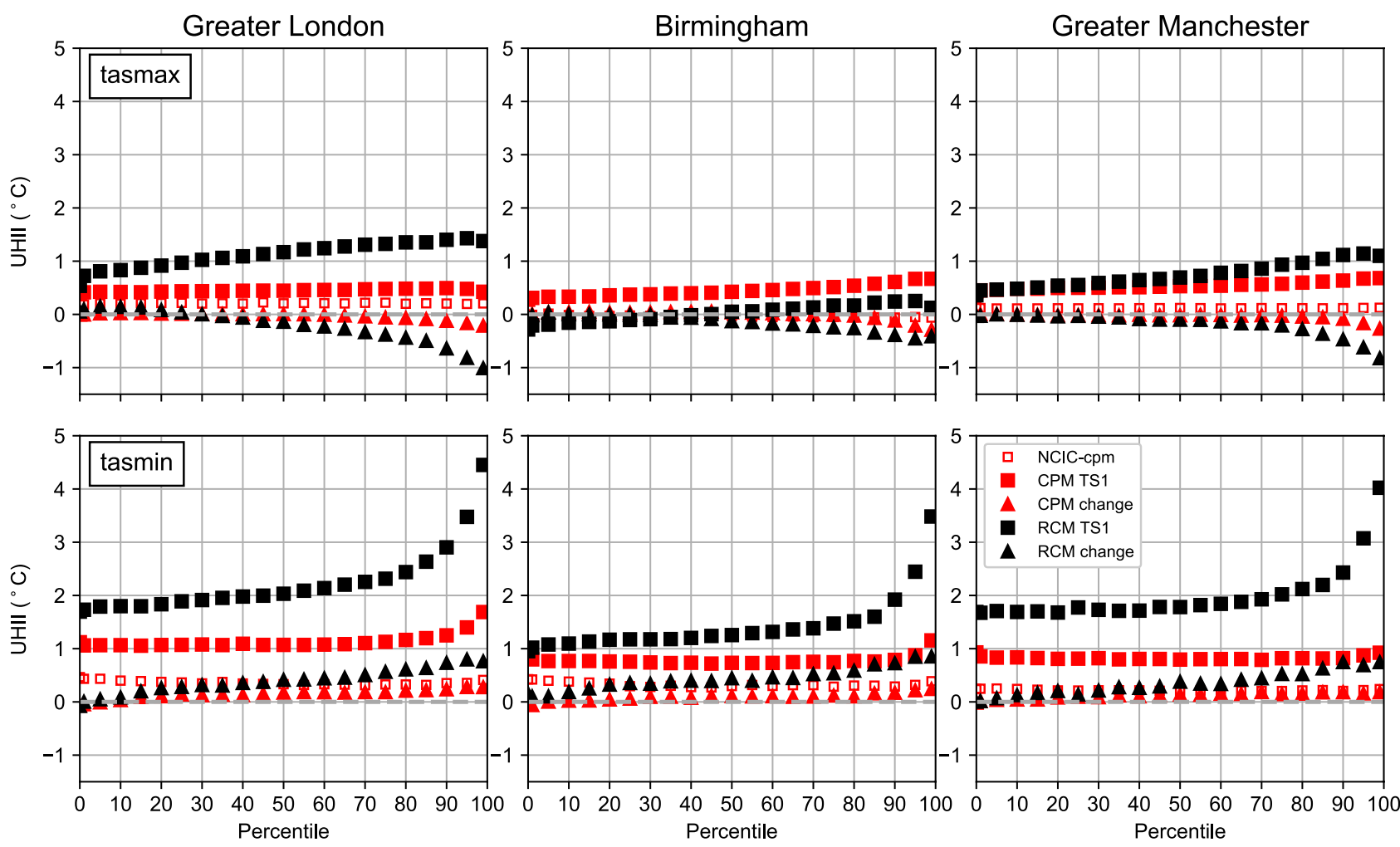

Fig. 7 Daytime (top) and night-time (bottom) observed (NCIC, red open squares), CPM (TS1, red squares; future changes, red triangles) and RCM (TS1, black squares; future changes, black triangles) estimates of the UHII 
by up to $1{ }^{\circ} \mathrm{C}$. While there is a slight reduction in future CPM UHII for the hottest days over Manchester, for both London and Birmingham it is unchanged. These figures provide strong evidence that the RCM is not correctly representing the urban influence, particularly for the warmest nights.

\subsection{Diurnal cycle of the urban influence}

Until now, we have focused exclusively on daily maximum and minimum temperatures. In this section, we study hourly temperature, including the diurnal cycle of the urban influence for these cities. Figure 8 shows the average CPM and RCM diurnal cycles on the hottest days for each city, defined as when the city-average daily-maximum temperature exceeds the 99th percentile, coloured by the city-averaged urban signal for each hour on these days. For all cities, the CPM peak temperatures are larger than the RCM and the timing earlier. This is because the higher thermal inertia in urban areas in the RCM reduces the amplitude and delays the phasing of the sensible heat flux. There is a clear diurnal cycle of the urban signal in the RCM, with urban areas much warmer than surrounding rural areas from mid-afternoon until sunrise the following morning. An urban "cool island" effect is observed for Greater London and Birmingham after sunrise, where the higher thermal inertia of the urban fabric results in slower warming compared to the rural surroundings. In the CPM, a small but positive urban heat island effect is observed from mid-afternoon until sunrise the following day for all cities, but the urban area warms at a more similar rate to rural surroundings after sunrise, resulting in a comparatively small urban signal. This behaviour, and the larger peak temperatures in the CPM are likely the result of the separate treatment of roofs (which have thermal properties more similar to rural areas) and street canyons in the MORUSES urban scheme, which results in earlier phasing and larger amplitude of the sensible heat fluxes. Unlike in the RCM, an urban cool island does not typically occur in the CPM. In general, the one-tile urban scheme in the RCM causes the sensible heat flux to become positive too late in the morning and the more flexible MORUSES scheme in the CPM allows an earlier increase in the sensible heat flux after the morning transition due to the more rapid warming of the roof (Oke 2002; Bohnenstengel et al. 2011). After reaching maximum temperatures, urban temperatures decrease more slowly than rural areas, but more rapidly compared to the RCM, resulting in a smaller UHI effect. The diurnal temperature range is also larger in the CPM than the RCM, which is mostly the result of the warmer maximum temperatures and the ability of the
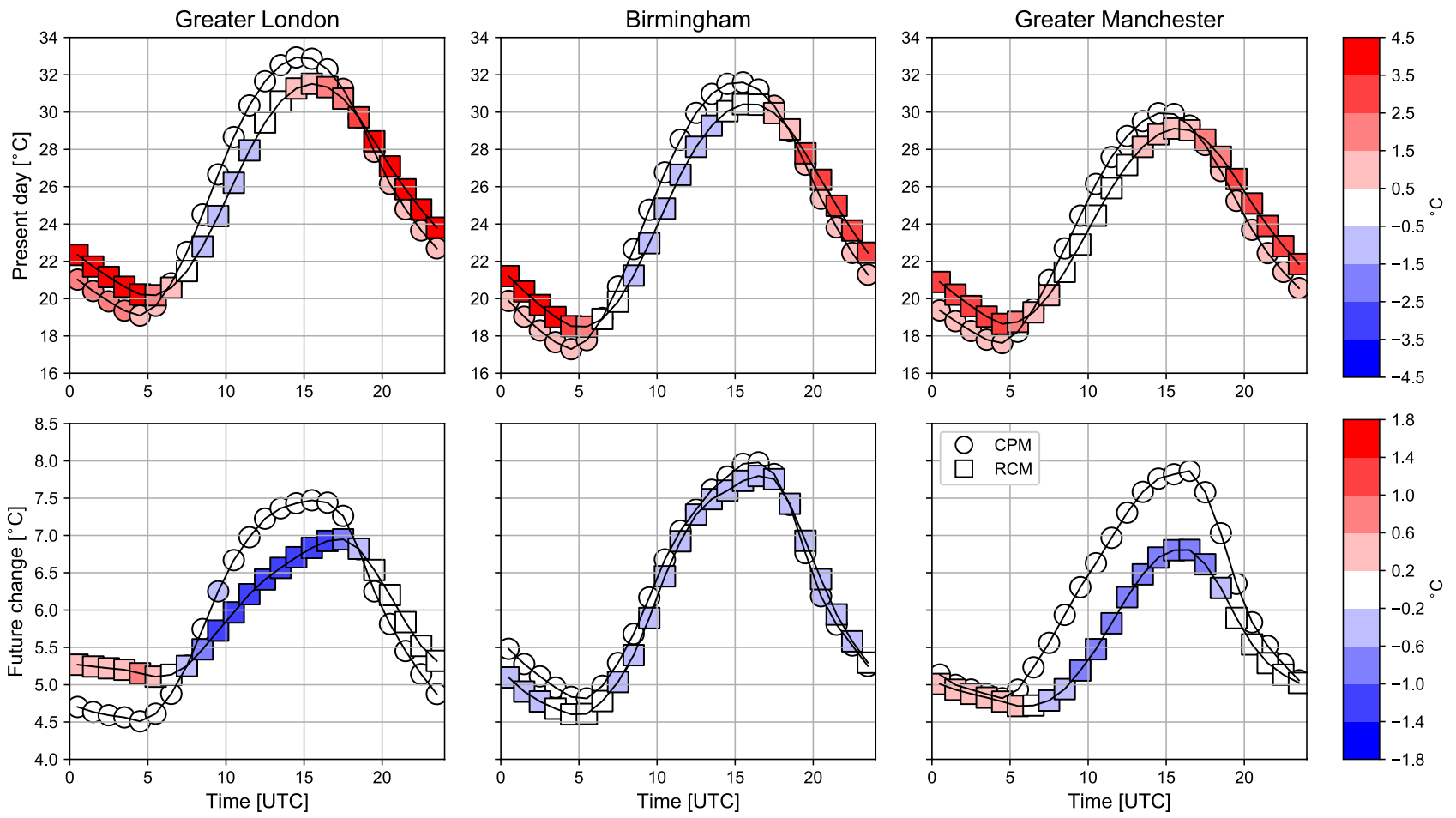

Fig. 8 Diurnal cycles of urban and rural temperatures on hot days (top panels) and future changes in urban and rural diurnal cycles on hot days (bottom panels) for the RCM (squares) and CPM (circles), for London, Birmingham and Manchester. Marker colours indicates the urban influence 
roof tile to warm up more quickly than the urban slab in the RCM.

In terms of future changes, all cities show a larger warming around peak temperatures in the CPM compared to the RCM. For Greater London, night-time temperatures (between 18:30 and 07:30 UTC) are projected to increase more in the RCM than the CPM. After sunrise, future changes in urban temperatures increase more in the CPM than the RCM, while the urban influence decreases in the RCM. Interestingly, the magnitude of the future changes in urban influence in the RCM are similar in magnitude to the differences in absolute changes between the CPM and RCM. This suggests that the urban influence in the RCM is dampening the future diurnal cycle, resulting in smaller future increases of daytime temperatures and larger increases in night-time temperatures than in the CPM. For Birmingham, the RCM urban temperatures increase by similar amounts to the CPM, however, the urban signal is reduced for most hours of the day. For Manchester, the difference between the CPM and RCM warming magnitudes is largest, with CPM temperatures warming by as much as $2{ }^{\circ} \mathrm{C}$ more than the RCM during the afternoon. Similar behaviour to Greater London in terms of an increased urban heat island at night and cool-island during the early morning is observed. A small decrease in the future urban influence in the CPM is observed mid-morning (09:30 UTC) for London, but for all other hours and cities it is unchanged.

\section{Discussion}

The results presented here illustrate a clear difference in the urban influence on temperature extremes in the RCM and CPM, particularly during the warmest nights. Temperatures in the RCM are influenced much more strongly by urban areas compared to the CPM or observations. Understanding this behaviour is important, as correctly quantifying changes to the frequency and severity of temperature extremes for warm nights is needed in order to understand future exposure of urban inhabitants to heat-stress. The better agreement of the urban signal in the CPM with observations during the hottest days and warmest nights is likely driven by a combination of the improved CEH (ITE) land-cover dataset and the MORUSES urban scheme used, which is known to more accurately capture the amplitude and phase of the sensible heat fluxes (Bohnenstengel et al. 2011, 2014; Murphy et al. 2018) than the simpler (Best 2005) one-tile scheme (Hertwig et al. 2020). The improved phasing of the sensible heat flux in MORUSES is driven by the separate representation of roofs and street canyons. Roofs are characterised by a small thermal inertia, meaning they warm up more rapidly than street canyons and at a more similar rate to rural surfaces. This advances the timing of the grid-box average sensible heat flux, reducing the urban/rural contrast hence the magnitude of the urban signal. This is in contrast to the Best (2005) scheme, which uses a large, fixed value for the bulk area heat capacity of $0.28 \mathrm{MJK}^{-1} \mathrm{~m}^{-2}$; a large thermal inertia dampens the sensible heat flux diurnal cycle leading to a lower, but later peak which likely causes the strong nighttime UHII effect. The large thermal inertia of urban areas in the RCM is likely responsible for the producing the urban cool island effect seen in Fig. 8 for London and Birmingham. The influence of urban areas in the RCM is too strong despite the omission of anthropogenic heat flux in the (Best 2005) scheme.

Another key driver of urban influence difference is the different land-cover datasets used by each model. Typically, city urban fractions are larger in the IGBP dataset compared with the CEH dataset (Fig. 1). Urban classification within the IGBP dataset is known to be questionable (Loveland et al. 2000), based on outdated maps from the 1960s to 1980s (Danko 1992), further supporting the use of the CPM over RCM. However, this difference in land-cover dataset alone does not explain the larger urban influence in the RCM. Figure S1 shows how, for a given urban fraction, the 99th percentile of both daytime and night-time UHII tends to be much larger in the RCM than the CPM (note that this is not the same metric as that described in Sect. 5 and shown in Figs. 4 and 5). However, such a comparison does not account for other land cover differences between the two datasets that will alter the atmospheric response, nor differences in the boundary layer depth over which heat is mixed, or the effect of advection and history of an air mass approaching an urban area, which are important (Bohnenstengel et al. 2011). The MORUSES urban morphology is based on empirical polynomial relations (Bohnenstengel et al. 2011) derived from high-resolution 3D Virtual London dataset (Evans et al. 2006). The low biases in the hottest days and warmest nights (Figs. 2 and 3 ) in the CPM over urban areas suggests these relationships are applicable to other UK cities. However, note that modelled temperatures are representative of temperatures somewhere above roof level (above displacement and roughness length) so are not directly comparable with observed temperatures which are made at $1.25 \mathrm{~m}$ above the ground. Note also that these simulations do not take into account future urban morphology. As cities are projected to grow in population and size in future, the strength of the urban influence is likely underestimated in these simulations.

The similar rates of urban and rural warming and relatively unchanged urban influence in the CPM agrees with the findings of McCarthy et al. (2012), while the amplification of the urban influence in the RCM corroborates the findings of Lo et al. (2020), who found greater rates of urban compared to rural warming during night-time and greater rates of rural compared to urban warming during the daytime in the 
UKCP RCM. However, the relatively unchanged urban influence in the CPM seen here lends support to their conclusion (when comparing their results to selected models from the European branch of the Coordinated Regional Downscaling Experiment (Jacob et al. 2014)), that these trends are specific to the UKCP18-regional configuration.

To better understand the causes of the different rates of warming for rural and urban areas in the RCM compared to the CPM, we have also analysed soil moisture and maximum hourly mean heat fluxes during the hottest days (Fig. S2). While both configurations use the JULES land surface scheme, the CPM uses TOPMODEL, a topography based rainfall-run off model to represent soil moisture heterogeneity throughout the soil column (Beven and Kirkby 1979), instead of the probability distributed model (Moore 2007) hydrology scheme used in the RCM. This results in presentday soils being drier in the CPM than the RCM, in better agreement with observations (Kendon et al. 2019). As a result, sensible heat fluxes $\left(Q_{H}\right)$ and Bowen ratios in the present-day are typically larger in the CPM than the RCM, which contributes to the higher UK-average CPM rural background temperature of $28.2{ }^{\circ} \mathrm{C}$ compared to $27.5^{\circ} \mathrm{C}$ in the RCM (Fig. 4). In future, while soils become drier in both models, RCM soils dry out more (particularly in Southeast England) and transition into a moisture-limited regime (Kendon et al. 2019), exacerbating increases in the Bowen ratio (note Bowen ratio changes are expressed as a factor). However, this is coupled with a lack of an increase in Bowen ratio over cities in the RCM, while in the CPM Bowen ratios increase in both rural and urban areas. This can partly be explained by the more detailed ITE land cover data in the CPM, which better represents more sub-grid scale vegetated fractions in cities allowing removal of soil moisture via the latent heat flux. In the RCM, the IGBP land cover dataset assumes larger fractions of impervious land cover and underestimates vegetation. Consequently, the Bowen ratio changes less in the future in the RCM. Thus, the reduced daytime urban signal in the RCM in future is caused by a strengthening in the rural/urban Bowen ratio gradient, influenced by both soil moisture and the urban scheme. In contrast, Bowen ratios increase everywhere in the CPM, including urban areas where the two-tile urban scheme better represents the surface energy balance, which results in an unchanged urban signal. In addition, the CEH (ITE) land cover data in the CPM has larger sub-grid scale variability for impervious (urban) and vegetated grid boxes in urban areas. The larger fraction of sub-grid scale vegetation allows a larger change in the Bowen ratio compared to the RCM using IGBP data which has less sub-grid scale vegetation present. Despite the larger drying of RCM soils, UK-average rural-reference temperatures still warm more in the CPM compared to the RCM (Fig. 4). This could be caused by differences in other variables such as cloud cover or differences in rainfall patterns caused by the different representations of convection, the study of which is beyond the scope of this paper. Although here we are primarily interested in urban temperatures, this study highlights the importance rural temperatures have in determining the urban influence. Improving the representation of land-surface processes (which strongly effect rural temperatures), such as soil-moisture precipitation feedbacks is a key challenge and currently an area of significant research [e.g., Kendon et al. (2021)]. Additional improvements in this area can be expected in the coming years.

The new urban signal extraction methodology has a number of advantages over existing methodologies. However, care must be taken in its use. Orographic influences on rural temperatures are not taken into account. Many cities are situated in valleys, such as London, which will tend to be warmer than surrounding higher ground, thus interpolation of these temperatures will result in cooler rural estimates and overestimated urban signals. Also, it requires choosing a suitable urban fraction threshold to produce a rural-reference dataset. An urban threshold of 0.1 was chosen in this study as it was found to accurately identify major UK urban areas, however the urban influence will be sensitive to this choice. Figure $\mathrm{S} 3$ shows the impact of varying the urban threshold from 0.05 to 0.2 on the UHII during hot days and warm nights. The primary effect of changing the urban threshold is to change the areal extent of urban areas; decreasing the urban threshold leads to larger urban areas and typically an increase in the UHII, while increasing it leads to smaller and weaker UHII. The impact is most pronounced at the relatively coarse RCM resolution (particularly in the daytime UHII), where reducing the urban threshold tends to create larger contiguous urban areas, an effect further compounded by the generally larger urban fractions in the IGBP dataset. This can lead to larger sensitivity, for example by increasing the influence of rural grid boxes further from the urban centres used to estimate the urban signal. While varying the urban threshold does lead to small changes to the magnitude of the UHII, it does not alter the interpretation or conclusions of the results.

While quantifying the UHII is helpful for understanding model processes, it is absolute temperatures that are more important from a public health perspective. This study shows, particularly for London, future daytime increases in urban temperatures would be underestimated and night-time temperatures overestimated without the improved representation of cities offered by the CPM. This is also manifested in terms of future absolute temperatures, with an underestimation in daytime and overestimation in night-time future temperatures. The implications are that the impact of hot days on the health of urban inhabitants would be underestimated, but so too would the ability of urban inhabitants to recover from this extreme heat during the night. The larger 
amplitude of diurnal cycles in the CPM could also have considerable implications for future building design.

\section{Conclusions}

Additional heat-stress in a warming climate will increase the risk of heat-related mortality. In this paper, we quantify the urban influence on extreme UK city temperatures in the latest UK Climate Projections. A new method to extract the urban influence on temperature has been developed, which allows urban signals to be extracted regardless of an urban areas size or location and without the need to choose appropriate rural and urban reference points.

We find that urban influence in the RCM is markedly different to the CPM, with present-day night-time urban temperatures too warm and the magnitude of night-time urban heat islands overestimated in the RCM, particularly for the warmest nights. In contrast, both daytime and night-time urban temperatures in the CPM, as well as the magnitude of urban heat islands, are in much greater agreement with observations. This improvement is predominantly the result of the improved urban scheme used in the CPM, which uses separate sub-grid scale tiles to represent street canyons and roofs which leads to improved phasing and amplitude of the diurnal cycle of heat fluxes. The higher resolution will also allow better representation of local spatial detail, but this has not been examined here.

In terms of future changes, there is a strong amplification of the night-time urban influence in the RCM, with urban temperatures warming significantly more than rural temperatures. This amplifies the night-time warm bias that exists in the present-day night-time RCM temperatures. Conversely, in the CPM, urban and rural temperatures warm at similar rates for both day and night, resulting in an unchanged urban influence. However, the urban temperatures themselves are still warmer and warm by more in future compared to the RCM. We find that the future reduction in the urban influence on daytime temperatures in the RCM is caused, at least in part, by drying soils and corresponding changes to rural sensible and latent heat fluxes, highlighting the importance of the accurate representation of soil moisture and hydrological processes for urban heat island studies. Further work is needed to fully understand the processes that are responsible for the difference in urban influence between the CPM and RCM. Nevertheless, the results here indicate that the CPM provides more reliable urban temperature projections through additional spatial resolution and the use of a two-tile urban scheme. It would be valuable in a future study to disentangle the effects of increased resolution (and other configuration differences between the CPM and RCM) and the improvement that is due to the two-tile urban scheme.
For the next generation of UKCP, as well as other urban climate modelling studies, a key recommendation is to implement a two-tile urban scheme even in coarse resolution models (without going down to convection-permitting resolution). This will be aided in future by the development of improved urban morphological datasets, potentially at the global scale, which could become available in the next few years.

Supplementary Information The online version contains supplementary material available at https://doi.org/10.1007/s00382-021-05883-w.

Acknowledgements We would like to thank Humphrey Lean for the many helpful discussions during the writing of this paper. The UK Climate Resilience programme is supported by the UKRI Strategic Priorities Fund. The programme is co-delivered by the Met Office and NERC on behalf of UKRI partners AHRC, pngRC, ESRC. E. J. Kendon gratefully acknowledges funding from the Joint UK BEIS/Defra Met Office Hadley Centre Climate Programme (Grant no. GA01101). This work and its contributor Sylvia I. Bohnenstengel were supported by the UK-China Research and Innovation Partnership Fund through the Met Office Climate Science for Service Partnership (CSSP) China as part of the Newton Fund.

Funding The UK Climate Resilience programme is supported by the UKRI Strategic Priorities Fund. The programme is co-delivered by the Met Office and NERC on behalf of UKRI partners AHRC, pngRC, ESRC. E. J. Kendon gratefully acknowledges funding from the Joint UK BEIS/Defra Met Office Hadley Centre Climate Programme (Grant no. GA01101). This work and its contributor Sylvia I. Bohnenstengel were supported by the UK-China Research and Innovation Partnership Fund through the Met Office Climate Science for Service Partnership (CSSP) China as part of the Newton Fund.

Availability of data and materials UKCP18-regional data on a 12-km grid over the United Kingdom are available online (https://catalogue. ceda.ac.uk/uuid/589211abeb844070a95d061c8cc7f604). UKCP18local data at $2.2 \mathrm{~km}$ resolution is also available online (https://catal ogue.ceda.ac.uk/uuid/d5822183143c4011a2bb304ee7c0baf7).

\section{Declarations}

Conflict of interest No conflicts of interest.

Code availability Custom code. Can be available on request.

Open Access This article is licensed under a Creative Commons Attribution 4.0 International License, which permits use, sharing, adaptation, distribution and reproduction in any medium or format, as long as you give appropriate credit to the original author(s) and the source, provide a link to the Creative Commons licence, and indicate if changes were made. The images or other third party material in this article are included in the article's Creative Commons licence, unless indicated otherwise in a credit line to the material. If material is not included in the article's Creative Commons licence and your intended use is not permitted by statutory regulation or exceeds the permitted use, you will need to obtain permission directly from the copyright holder. To view a copy of this licence, visit http://creativecommons.org/licenses/by/4.0/. 


\section{References}

Allen L, Lindberg F, Grimmond C (2011) Global to city scale urban anthropogenic heat flux: model and variability. Int J Climatol 31(13):1990-2005

Arnfield AJ (2003) Two decades of urban climate research: a review of turbulence, exchanges of energy and water, and the urban heat island. Int J Climatol: J Royal Meteorol Soc 23(1):1-26

Best M (2005) Representing urban areas within operational numerical weather prediction models. Bound-Layer Meteorol 114(1):91-109

Best M, Pryor M, Clark D, Rooney G, Essery R, Ménard C, Edwards J, Hendry M, Porson A, Gedney N et al (2011) The joint UK land environment simulator (Jules), model description-part 1: energy and water fluxes. Geosci Model Dev 4(1):677-699

Beven KJ, Kirkby MJ (1979) A physically based, variable contributing area model of basin hydrology/un modèle à base physique de zone d'appel variable de l'hydrologie du bassin versant. Hydrol Sci J 24(1):43-69

Bohnenstengel S, Evans S, Clark PA, Belcher S (2011) Simulations of the London urban heat island. Q J Royal Meteorol Soc 137(659): 1625-1640

Bohnenstengel S, Hamilton I, Davies M, Belcher S (2014) Impact of anthropogenic heat emissions on london's temperatures. Q J Royal Meteorol Soc 140(679):687-698

Danko DM (1992) The digital chart of the world project. Photogramm Eng Remote Sens 58(8):1125-1128

Essery R, Best M, Betts R, Cox PM, Taylor CM (2003) Explicit representation of subgrid heterogeneity in a gcm land surface scheme. J Hydrometeorol 4(3):530-543

Evans S, Hudson-Smith A, Batty M (2006) 3-d gis: Virtual london and beyond. an exploration of the $3-\mathrm{d}$ gis experience involved in the creation of virtual London. Cybergeo: Eur J Geogr

Fischer EM, Schär C (2010) Consistent geographical patterns of changes in high-impact European heatwaves. Nat Geosci 3(6):398-403

Fuller R, Groom G, Jones A (1994) The land-cover map of great Britain: an automated classification of landsat thematic mapper data. Photogramm Eng Remote Sens 60(5):553-562

Hajat S, Vardoulakis S, Heaviside C, Eggen B (2014) Climate change effects on human health: projections of temperature-related mortality for the UK during the 2020s, 2050s and 2080s. J Epidemiol Commun Health 68(7):641-648

Harman IN, Barlow JF, Belcher SE (2004a) Scalar fluxes from urban street canyons part ii: model. Bound-Layer Meteorol 113(3):387-410

Harman IN, Best MJ, Belcher SE (2004b) Radiative exchange in an urban street canyon. Bound-Layer Meteorol 110(2):301-316

Heaviside C, Cai XM, Vardoulakis S (2015) The effects of horizontal advection on the urban heat island in Birmingham and the west midlands, united kingdom during a heatwave. Q J Royal Meteorol Soc 141(689): 1429-1441

Heaviside C, Vardoulakis S, Cai XM (2016) Attribution of mortality to the urban heat island during heatwaves in the west midlands, UK. Environ Health 15(1):49-59

Hertwig D, Grimmond S, Hendry MA, Saunders B, Wang Z, Jeoffrion M, Vidale PL, McGuire PC, Bohnenstengel SI, Ward HC et al (2020) Urban signals in high-resolution weather and climate simulations: role of urban land-surface characterisation. Theoret Appl Climatol 142(1):701-728

Hollis D, McCarthy M, Kendon M, Legg T, Simpson I (2019) Hadukgrid-a new UK dataset of gridded climate observations. Geosci Data J 6(2):151-159

Husak GJ, Hadley BC, McGwire KC (1999) Landsat thematic mapper registration accuracy and its effects on the igbp validation. Photogramm Eng Remote Sens 65:1033-1040
Jacob D, Petersen J, Eggert B, Alias A, Christensen OB, Bouwer LM, Braun A, Colette A, Déqué M, Georgievski G et al (2014) Eurocordex: new high-resolution climate change projections for European impact research. Reg Environ Change 14(2):563-578

Jenkins GJ, Murphy JM, Sexton DM, Lowe JA, Jones P, Kilsby CG (2010) UK climate projections briefing report. Met Office Hadley Centre

Johnson H, Kovats RS, McGregor G, Stedman J, Gibbs M, Walton H, Cook L, Black E (2005) The impact of the 2003 heat wave on mortality and hospital admissions in England. Health Stat Q 25:6-11

Kendon E, Fosser G, Murphy J, Chan S, Clark R, Harris G, Lock A, Lowe J, Martin G, Pirret J, et al. (2019) Ukcp convection-permitting model projections: Science report. Met Office Hadley Centre

Kendon E, Prein A, Senior C, Stirling A (2021) Challenges and outlook for convection-permitting climate modelling. Phil Trans Royal Soc A 379(2195):20190,547

Kendon EJ, Roberts NM, Fowler HJ, Roberts MJ, Chan SC, Senior CA (2014) Heavier summer downpours with climate change revealed by weather forecast resolution model. Nat Climate Change 4(7):570-576

Lo YTE, Mitchell DM, Gasparrini A, Vicedo-Cabrera AM, Ebi KL, Frumhoff PC, Millar RJ, Roberts W, Sera F, Sparrow S et al (2019) Increasing mitigation ambition to meet the Paris agreement's temperature goal avoids substantial heat-related mortality in us cities. Sci Adv 5(6):eaau4373

Lo YTE, Mitchell DM, Bohnenstengel SI, Collins M, Hawkins E, Hegerl GC, Joshi M, Stott PA (2020) UK climate projections: Summer daytime and nighttime urban heat island changes in England's major cities. J Climate 33(20):9015-9030

Loveland TR, Reed BC, Brown JF, Ohlen DO, Zhu Z, Yang L, Merchant JW (2000) Development of a global land cover characteristics database and igbp discover from $1 \mathrm{~km}$ avhrr data. Int J Remote Sens 21(6-7):1303-1330

Lowe JA, Bernie D, Bett P, Bricheno L, Brown S, Calvert D, Clark R, Eagle K, Edwards T, Fosser G et al (2018) Ukcp18 science overview report. Met Office Hadley Centre, Exeter

Masson V (2000) A physically-based scheme for the urban energy budget in atmospheric models. Bound-Layer Meteorol 94(3):357-397

McCarthy M, Harpham C, Goodess C, Jones P (2012) Simulating climate change in UK cities using a regional climate model, hadrm3. Int J Climatol 32(12):1875-1888

Moore R (2007) The pdm rainfall-runoff model. Hydrol Earth Syst Sci 11(1):483-499

Murphy J, Harris G, Sexton D, Kendon E, Bett P, Clark R, Yamazaki K (2018) Ukcp18 land projections: Science report. Met Office Hadley Centre

Oke TR (1982) The energetic basis of the urban heat island. Q J Royal Meteorol Soc 108(455):1-24

Oke TR (2002) Boundary layer climates. Routledge

Oke TR, Mills G, Christen A, Voogt JA (2017) Urban climates. Cambridge University Press

Oleson KW, Bonan GB, Feddema J, Jackson T (2011) An examination of urban heat island characteristics in a global climate model. Int J Climatol 31(12):1848-1865

Porson A, Clark PA, Harman I, Best M, Belcher S (2010a) Implementation of a new urban energy budget scheme in the Metum. Part i: description and idealized simulations. Q J Royal Meteorol Soc 136(651):1514-1529

Porson A, Clark PA, Harman I, Best M, Belcher S (2010b) Implementation of a new urban energy budget scheme into Metum. Part ii: validation against observations and model intercomparison. Q J Royal Meteorol Soc 136(651):1530-1542 
Sailor DJ (2011) A review of methods for estimating anthropogenic heat and moisture emissions in the urban environment. Int J Climatol 31(2):189-199

Smith CL, Webb A, Levermore G, Lindley S, Beswick K (2011) Finescale spatial temperature patterns across a uk conurbation. Clim Change 109(3-4):269-286

UN DESA/Population Division (2018) World urbanization prospects 2018 - country profiles. united nations department of economic and social affairs. https://population.un.org/wup/Country-Profi les/, [accessed March-2021]

Vicedo-Cabrera AM, Guo Y, Sera F, Huber V, Schleussner CF, Mitchell D, Tong S, Coelho MSZS, Saldiva PHN, Lavigne E et al (2018) Temperature-related mortality impacts under and beyond Paris agreement climate change scenarios. Clim Change 150(3-4):391-402
Walters D, Baran AJ, Boutle I, Brooks M, Earnshaw P, Edwards J, Furtado K, Hill P, Lock A, Manners J et al (2019) The met office unified model global atmosphere 7.0/7.1 and Jules global land 7.0 configurations. Geosci Model Dev 12(5):1909-1963

Watkins R, Palmer J, Kolokotroni M, Littlefair P (2002) The London heat island: results from summertime monitoring. Build Serv Eng Res Technol 23(2):97-106

Wilby RL (2003) Past and projected trends in London's urban heat island. Weather 58(7):251-260

Publisher's Note Springer Nature remains neutral with regard to jurisdictional claims in published maps and institutional affiliations. 